\title{
Thermodynamic and Kinetic Analysis of Low- temperature Thermal Reduction of Graphene Oxide
}

\author{
Kuibo Yin ${ }^{1}$, Haitao $\mathrm{Li}^{2}$, Yidong $\mathrm{Xia}^{2}$, Hengchang $\mathrm{Bi}^{1}$, Jun Sun ${ }^{1}, \quad$ Zhiguo Liu ${ }^{2}, \quad$ Litao Sun ${ }^{1}$
}

(Received 6 April; Accepted 27 April; published online 6 May 2011.)

\begin{abstract}
The thermodynamic state and kinetic process of low-temperature deoxygenation reaction of graphene oxide (GO) have been investigated for better understanding on the reduction mechanism by using Differential Scanning Calorimetry (DSC), Thermogravimetry-Mass Spectrometry (TG-MS), and X-ray Photoelectron Spectroscopy (XPS). It is found that the thermal reduction reaction of GO is exothermic with degassing of $\mathrm{CO}_{2}, \mathrm{CO}$ and $\mathrm{H}_{2} \mathrm{O}$. Graphene is thermodynamically more stable than GO. The deoxygenation reaction of GO is kinetically controlled and the activation energy for GO is calculated to be $167 \mathrm{~kJ} / \mathrm{mol}(1.73 \mathrm{eV} /$ atom).
\end{abstract}

Keywords: Graphene oxide; Activation energy; Thermal deoxygenation

Citation: Kuibo Yin, Haitao Li, Yidong Xia, Hengchang Bi, Jun Sun, Zhiguo Liu and Litao Sun, "Thermodynamic and Kinetic Analysis of Low-temperature Thermal Reduction of Graphene Oxide", Nano-Micro Lett. 3 (1), 51-55 (2011). http://dx.doi.org/10.3786/nml.v3i1.p51-55

\section{Introduction}

Due to its excellent electrical, mechanical, and thermal properties, graphene, a single-atom-thick twodimensional sheet of $\mathrm{sp}^{2}$ bonded carbon, has shown a diverse range of potential applications from fieldeffect transistors to energy-related materials [1-5]. Various methods have been performed to produce graphene, such as micromechanical exfoliation [1], chemical vapour deposition (CVD) [3], and reduction of graphene oxide (GO). Among these strategies, reduction of GO, which derived from the oxidation and reduction of graphite, has attracted much attention, due to the advantages of low cost and capability for large scale production $[2,4]$. GO is a key intermediate from graphite to graphene, which contains many kinds of oxygen functional groups, including epoxide (C-O-C), single-bonded on-top oxygen (C-O), hydroxyl groups $(\mathrm{C}-\mathrm{OH})$, and carbonyl $(\mathrm{C}=\mathrm{O})$ [4]. Some functional groups exist at the surface of graphene and others are expected to form on the edges of the platelets. Tremendous efforts have been devoted to remove these oxygen functional groups via reduction processes for recovering the conjugated $\mathrm{sp}^{2}$ carbon network and the desirable properties of graphene.

As a green method, thermal reduction is more attractive than chemical reduction methods to obtain graphene from GO [6]. Usually, for dry GO, a considerable mass loss will occur near $200^{\circ} \mathrm{C}$ accompanied by releasing of $\mathrm{CO}_{2}, \mathrm{CO}$, and $\mathrm{H}_{2} \mathrm{O}$ due to the deoxygenation of oxygen functional groups [7]. Recently, it has been found that the deoxygenation temperature can be decreased to $150^{\circ} \mathrm{C}$ at atmospheric pressure when GO is dispersed in propylene carbonate [8] as well as in a mixture of water and organic solvents [9]. Meanwhile, other novel low-temperature thermal-related reduction methods have also been developed, such as flash re-

${ }^{1}$ SEU-FEI Nano-Pico Center, Key Laboratory of MEMS of Ministry of Education, Southeast University, Nanjing 210096, P. R. China. Fax: +86-25-83792939; Tel: +86-25-83793264 ext.8813

${ }^{2}$ Department of Materials Science and Engineering, National Lab of Solid State Microstructure, Nanjing University, Nanjing 210093, P. R. China.

*Corresponding author. E-mail: slt@seu.edu.cn 
duction [10,11], laser reduction [12], and hydrothermal and/or solvothermal reduction $[13,14]$. However, the reduction mechanisms are far from clear and the reaction process need to be further studied. Since all the above mentioned reduction methods are thermal-related and are based on the deoxygenation of oxygen functional groups, the investigation on the thermodynamic state and kinetic process of common thermal reduction will be beneficial to understanding each reduction mechanism of them.

Herein we investigate the temperature effect on GO reduction and the oxygen elimination processes of dry GO samples. DSC, TG-MS, and XPS are used to monitor the reaction process with different heating rates and various environmental factors. The thermodynamic state and kinetic process of the deoxygenation reaction of GO are discussed, and the activation energy for GO is estimated based on the experiments.

\section{Experimental}

GO was generated from chemical oxidation of graphite using the modified Hummers method [3] and exfoliated via bath sonication in aqueous solution for $1 \mathrm{~h}$. The dry GO samples were obtained by vacuum filter, followed by further drying at $60^{\circ} \mathrm{C}$ for $24 \mathrm{~h}$ at atmospheric pressure. GO sheets were heated for $15 \mathrm{~h}$ under three different conditions: deionized water in a sealed Teflon autoclave (hydrothermal method), vacuum in a sealed quartztube (with the pressure of several Pascal), and in the air directly.

The DSC measurements were performed in inert argon atmosphere using a Perkin Elmer Pyris 1 DSC system with a sample amount of approximately $5 \mathrm{mg}$. The samples were heated up to $350^{\circ} \mathrm{C}$ at several different heating rates. The reduction degree of GO was characterized by XPS (Thermo Scientific K-Alpha system). The TG-MS analysis was carried out using Netzsch STA 449C and QMS 403C system under argon atmosphere.

\section{Results and Discussion}

A typical DSC curve with the heating rate of $20^{\circ} \mathrm{C} / \mathrm{min}$ is shown in Fig. 1(a). A wide exothermic peak was found at around $210^{\circ} \mathrm{C}$. The activation energy can be obtained from Kissinger equation, which depicts the relationship between heating rate and peak temperature [15]:

$$
\frac{E_{a} V}{k T_{p}^{2}}=A e^{\frac{E_{a}}{k T_{p}}}
$$

where $E_{a}$ is the activation energy for the reduction reaction, $V$ is the heating rate, $k$ is Boltzmann's constant, $T_{p}$ is the peak temperature, and $A$ is the pre- exponential factor. Thus, the activation energy can be obtained from the slope of a straight-line fit to a plot of $\ln \left(\frac{T_{p}^{2}}{V}\right)$ versus $1 / T_{p}$. In this work, four different heating rates $\left(5,10,20\right.$, and $\left.25^{\circ} \mathrm{C} / \mathrm{min}\right)$ were employed. The results of $\ln \left(\frac{T_{p}^{2}}{V}\right)$ versus $1 / T_{p}$ are plotted in Fig. 1(b). The activation energy derived from these data is about $167 \mathrm{~kJ} / \mathrm{mol}(1.73 \mathrm{eV} /$ atom $)$, which is close to the value obtained by Ruoff et al from Arrhenius dependence (about $155 \mathrm{~kJ} / \mathrm{mol}(1.6 \mathrm{eV} /$ atom) for single-layer GO in UHV) [16].
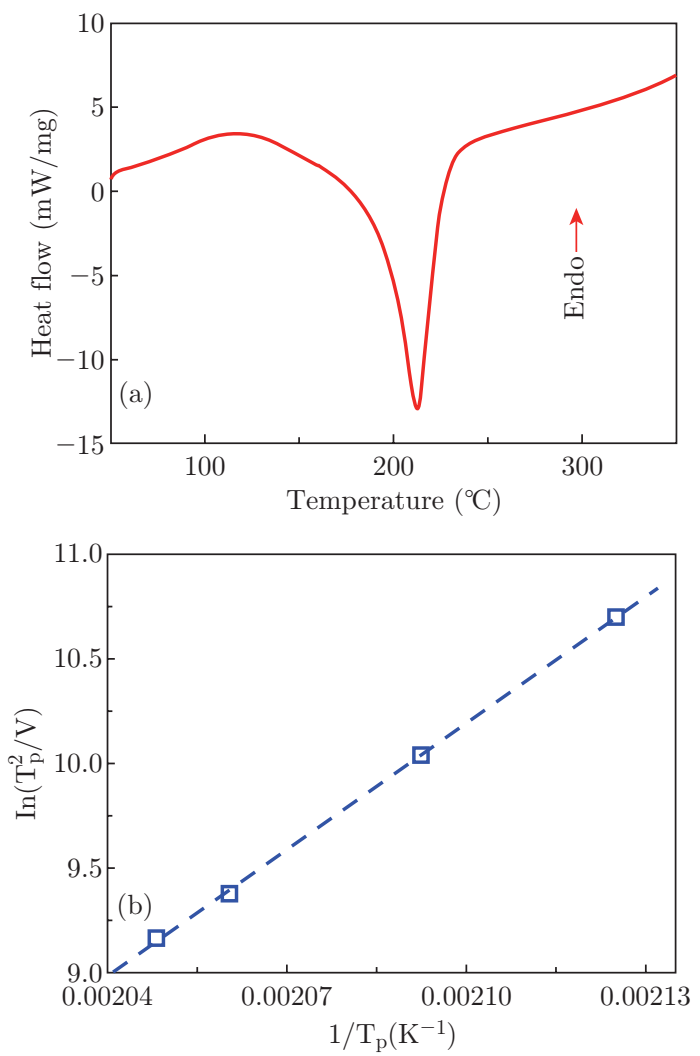

Fig. 1 A typical DSC curve of GO with a heating rate of $20^{\circ} \mathrm{C} / \min (\mathrm{a}) ; \ln \left(\frac{T_{p}^{2}}{V}\right)$ as a function of $1 / T_{p}(\mathrm{~b})$.

During the exothermic reaction, it has been found that a dramatic mass loss occurs due to the degassing of $\mathrm{CO}, \mathrm{H}_{2} \mathrm{O}$, and $\mathrm{CO}_{2}[7,16]$. Similar results were found in our TG-MS experiment and the MS data were semilogarithmically plotted in Fig. 2. Each of the signals of $\mathrm{CO}, \mathrm{H}_{2} \mathrm{O}$, and $\mathrm{CO}_{2}$ has a dramatical increase when the external temperature reaches near $180^{\circ} \mathrm{C}$ with the heating rate of $10^{\circ} \mathrm{C} / \mathrm{min}$. The signal of $\mathrm{H}_{2} \mathrm{O}$ exists at the beginning of this experiment, which may derive from the release of adsorbed water. It is interesting to note that $\mathrm{CO}_{2}$ has already been detected even at $130^{\circ} \mathrm{C}$, which indicates that the deoxygenation reaction of GO has already been triggered below $130^{\circ} \mathrm{C}$. 


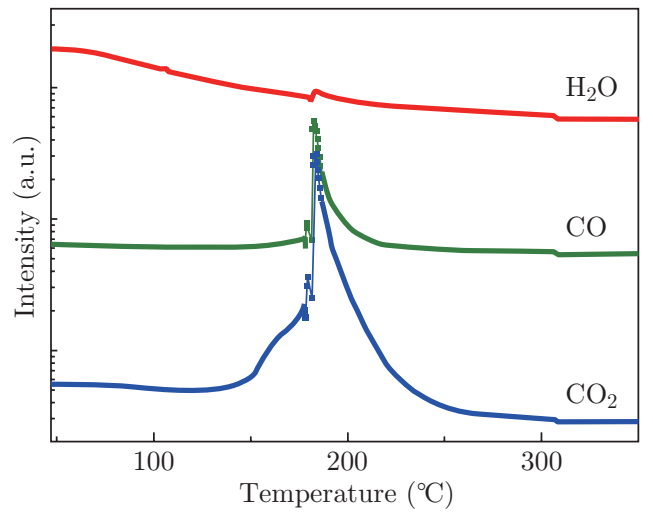

Fig. 2 The Mass Spectra of $\mathrm{H}_{2} \mathrm{O}, \mathrm{CO}$, and $\mathrm{CO}_{2}$ as a function of temperature with a heating rate of $10^{\circ} \mathrm{C} / \mathrm{min}$, respectively.

Due to the degassing of $\mathrm{CO}_{2}, \mathrm{CO}$ and $\mathrm{H}_{2} \mathrm{O}$ which are more random than solid state, the entropy change of the deoxygenation reaction of GO must be positive. Meanwhile, the enthalpy change is negative as the deoxygenation reaction is exothermic. Therefore, the change of Gibbs free energy of this system must be negative from the equation $\Delta \mathrm{G}=\Delta H-T \cdot \Delta S$. Consequently, the deoxygenation reaction of GO should be spontaneous in thermodynamics, which implies that the deoxygenation reaction can occur under relatively lowtemperature conditions. Since the relationship between reaction rate and temperature is exponential [16], we deduce that the rate of deoxygenation reaction at low temperature would be slow.

Figure 3 shows the $\mathrm{C}$ 1s XPS results of GOs before and after reduction under various environmental factors (deionized water in a sealed Teflon autoclave, vacuum in a sealed quartztube, and in the air). The peak near $284.5 \mathrm{eV}$ corresponds to $\mathrm{C}-\mathrm{C}$ binding and the peaks shifting positively about $1.5 \sim 4.0 \mathrm{eV}$ are assigned for $\mathrm{C}-\mathrm{OH}, \mathrm{C}=\mathrm{O}$, and $\mathrm{O}=\mathrm{C}-\mathrm{OH}$, respectively [4]. Figure 3 (a) shows the $\mathrm{C} 1 \mathrm{~s}$ XPS results of the GO heated at $95^{\circ} \mathrm{C}$ and the corresponding result of as-prepared GO is also included for comparison. Obviously, all the three samples have been partially reduced after $15 \mathrm{~h}$ at $95^{\circ} \mathrm{C}$ because all the intensity ratios of $\mathrm{I}_{\mathrm{C}-\mathrm{OH}} / \mathrm{I}_{\mathrm{C}-\mathrm{C}}$ decrease, which implies that the low-temperature deoxygenation reation of GO is feasible. With reduction temperature increasing, the reduction degrees have been significantly improved since the peak intensities of $\mathrm{C}-\mathrm{OH}$ have been extensively decreased, as shown in Figs. 3(b) and $3(\mathrm{c})$. It is obvious that the peak intensities of $\mathrm{C}=\mathrm{O}$ and $\mathrm{O}=\mathrm{C}-\mathrm{OH}$ are much lower than those of $\mathrm{C}-\mathrm{C}$ and $\mathrm{C}-\mathrm{OH}$ in $\mathrm{GO}$. As a result, we can define the intensity ratio of $\mathrm{I}_{\mathrm{C}-\mathrm{OH}} / \mathrm{I}_{\mathrm{C}-\mathrm{C}}$ as a simple parameter to demonstrate the reduction degree. From Fig. 3(d) we can readily see that, with temperature increasing, the reduction degree increases until a balance reaches for all samples. At relative low temperature, the most effective reduction method is hydrothermal method, heating
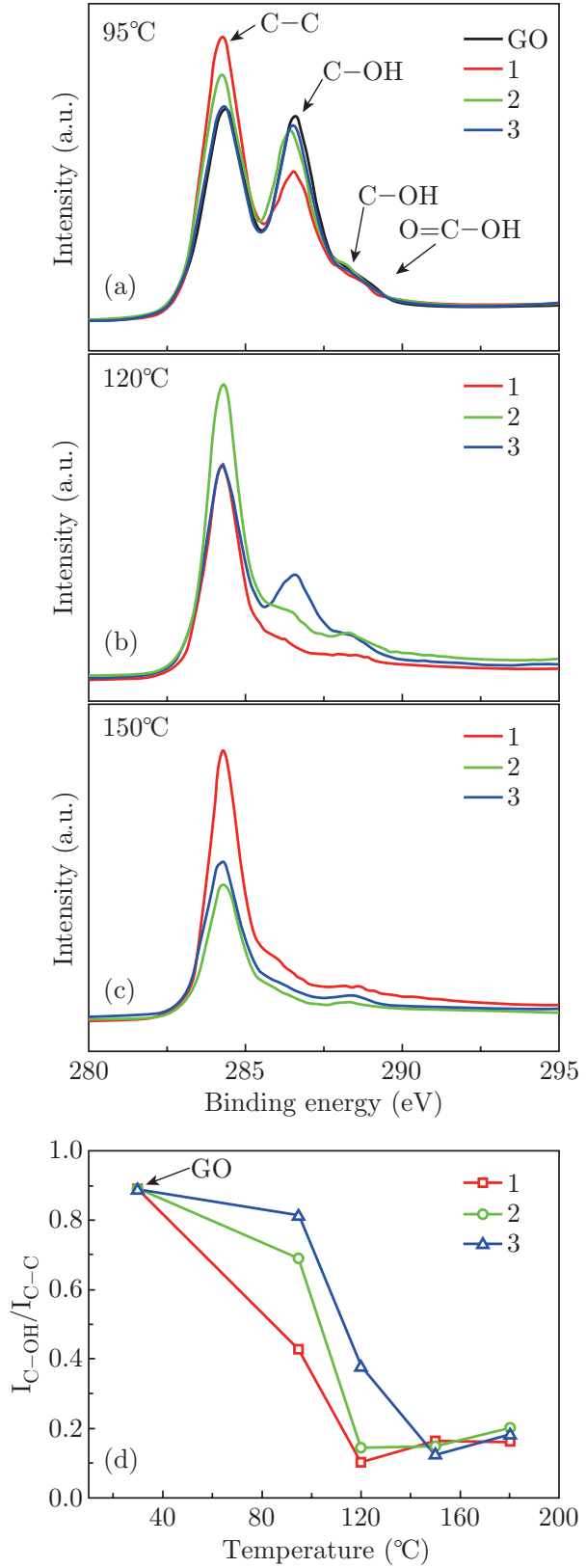

Fig. 3 C 1s XPS results of GO reduced under different temperature: $95^{\circ} \mathrm{C}(\mathrm{a}), 120^{\circ} \mathrm{C}(\mathrm{b})$, and $150^{\circ} \mathrm{C}$ (c); the intensity ratio of $\mathrm{C}-\mathrm{OH}$ and $\mathrm{C}-\mathrm{C}$ peaks as a function of temperature (d). The samples were placed 1: under deionized water in a sealed Teflon autoclave (hydrothermal method), 2: under vacuum in a sealed quartz tube (with the pressure of several Pascal), and 3: in the air directly.

under vacuum the second and heating in the air the third. For hydrothermal method, the viscosity of water will decrease and the convection ability as well as the ion molecules will increase with temperature increasing [17], which might accelerate the deoxygenation reaction. Since solid GO can degas, this reaction will proceed faster under vacuum than at ambient pressure. It should be noted that when the temperature reaches or exceeds $150^{\circ} \mathrm{C}$, the reduction degrees are nearly com- 
parable for all the three methods. Thus, temperature plays an important role in the reduction rate. At relative low temperature, the reduction rate is relative slow and only partial reductions of GOs have been performed within the reaction time of $15 \mathrm{~h}$ for all the three methods. The reaction rate increases with increasing temperature and the reduction degree sharply rises within the same reaction time scale. When the deoxygenation reaction is nearly complete, the role of rising temperature can be ignored.

The change of potential energy of GO during thermal reduction is sketched in Fig. 4. The average energy of oxygenated functional groups must be improved equal to or greater than $167 \mathrm{~kJ} / \mathrm{mol}$ before the occurrence of deoxygenation reaction. On the other hand, since carbon loss during reduction was found in our TG-MS experiment, carbon vacancies must form in the matrix of the reduced GO, as illustrated in the inset of $\mathrm{r}-\mathrm{GO}$ in Fig. 4. Therefore, in order to obtain highly ordered graphene, the reduced GO from thermal reduction reaction need to be further improved [18].

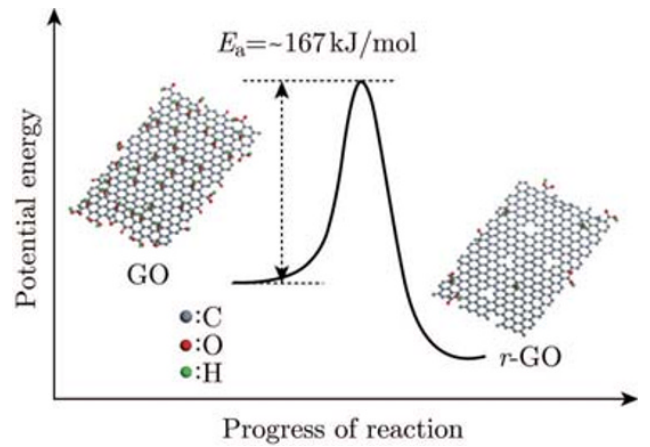

Fig. 4 Schematic representation of the potential energy as a function of progress of reaction of GO; the schematic structures of GO and reduced graphene oxide (r-GO) are also shown.

\section{Conclusions}

In conclusion, the reduction thermodynamics and kinetics of GO have been investigated by thermal treatment. The deoxygenation reaction of GO is kinetically controlled and the activation energy of this reaction was calculated as $1.73 \mathrm{eV} /$ atom. At relatively low temperature, hydrothermal method is more effective to reduce GO than the other two methods and the method of heating under vacuum is more effective than that of heating in air. When the temperature reaches and exceeds $150^{\circ} \mathrm{C}$, the degree of reduction are nearly comparable for all the three methods. Meanwhile, the degassing temperature of $\mathrm{CO}_{2}$ is lower than that of other gases.

\section{Acknowledgements}

This work was supported by the National Basic Research Program of China (Grant Nos. 2011CB707601 and 2009CB623702), the National Natural Science Foundation of China (Grant Nos. 51071044, 60976003 and 61006011), China Postdoctoral Science Foundation Funded Project (Grant No. 20100481085), Jiangsu Planned Projects for Postdoctoral Research Funds (Grant No. 1001014B), and Open Research Fund of State Key Laboratory of Bioelectronics.

\section{References}

[1] K. S. Novoselov, A. K. Geim, S. V. Morozov, D. Jiang, Y. Zhang, S. V. Dubonos, I. V. Grigorieva and A. A. Firsov, Science 306, 666 (2004). http://dx.doi.org/ 10.1126/science. 1102896

[2] S. Park and R. S. Ruoff, Nat. Nanotech. 4, 217 (2009). http://dx.doi.org/10.1038/nnano.2009.58

[3] X. S. Li, W. W. Cai, J. An, S. Kim, J. Nah, D. X. Yang, R. Piner, A. Velamakanni, I. Jung, E. Tutuc, S. K. Banerjee, L. Colombo and R. S. Ruoff, Science 324, 1312 (2009). http://dx.doi.org/10.1126/ science. 1171245

[4] D. R. Dreyer, S. Park, C. W. Bielawski and R. S. Ruoff, Chem. Soc. Rev. 39, 228 (2010). http://dx.doi.org/ 10.1039/b917103g

[5] L. Kou, H. K. He and C. Gao, Nano-Micro Lett. 2, 177 (2010). http://dx.doi.org/10.5101/nml.v2i3. p177-183

[6] X. F. Gao, J. Jang and S. Nagase, J. Phys. Chem. C 114, 832 (2010). http://dx.doi.org/10.1021/ jp909284g

[7] M. J. McAllister, J. L. Li, D. H. Adamson, H. C. Schniepp, A. A. Abdala, J. Liu, M. H.-Alonso, D. L. Milius, R. Car, R. K. Prudhomme and I. A. Aksay, Chem. Mater. 19, 4396 (2007). http://dx.doi.org/ $10.1021 / \mathrm{cm} 0630800$

[8] Y. Zhu, M. D. Stoller, W. Cai, A. Velamakanni, R. D. Piner, D. Chen, and R. S. Ruoff, ACS Nano 4, 1227 (2010). http://dx.doi.org/10.1021/nn901689k

[9] W. F. Chen and L. F. Yan, Nanoscale 2, 559 (2010). http://dx.doi.org/10.1039/b9nr00191c

[10] S. Gilje, S. Dubin, A. Badakhshan, J. Farrar, S. A. Danczyk and R. B. Kaner, Adv. Mater. 22, 419 (2009). http://dx.doi.org/10.1002/adma. 200901902

[11] L. J. Cote, R. Cruz-Silva and J. X. Huang, J. Am. Chem. Soc. 131, 11027 (2009). http://dx.doi.org/ 10. $1021 /$ ja902348k

[12] Y. L. Zhang, L. Guo, S. Wei, Y. Y. He, H. Xia, Q. D. Chen, H. B. Sun and F. S. Xiao, NanoToday 5, 15 (2010). http://dx.doi.org/10.1016/j.nantod. 2009.12.009

[13] Y. Zhou, Q. L. Bao, L. A. L. Tang, Y. L. Zhong and K. P. Loh, Chem. Mater. 21, 2950 (2009). http://dx. doi.org/10.1021/cm9006603 
[14] C. Nethravathi and M. Rajamathi, Carbon 46, 1994 (2008). http://dx.doi.org/10.1016/j.carbon. 2008.08.013

[15] K. B. Yin, Y. D. Xia, C. Y. Chan, W. Q. Zhang, Q. J. Wang, X. N. Zhao, A. D. Li, Z. G. Liu, M. W. Bayes and K. W. Yee, Scripta Mater. 58, 65 (2008). http:// dx.doi.org/10.1016/j.scriptamat.2007.08.028

[16] I. Jung, D. A. Field, N. J. Clark, Y. W. Zhu, D. X. Yang, R. D. Piner, S. Stankovich, D. A. Dikin, H. K.
Geisler, C. A. Ventrice Jr and R. S. Ruoff, J. Phys. Chem. C 113, 18480 (2009). http://dx.doi.org/10. 1021/jp904396j

[17] S. Deguchi, S. K. Ghosh, R. G. Alargova and K. Tsujii, J. Phys. Chem. B 110, 18358 (2006). http://dx.doi. org/10.1021/jp062045d

[18] A. Bagri, C. Mattevi, M. Acik, Y. J. Chabal, M. Chhowalla and V. B. Shenoy, Nat. Chem. 2, 581 (2010). http://dx.doi.org/10.1038/nchem. 686 